\title{
Analysis on Improving the Schooling Quality and Level of Local Universities
}

\author{
Lin $\operatorname{Lin}^{1, a}$ \\ ${ }^{1}$ Institute for Higher Education, Jilin Agricultural University, Changchun,130118, China \\ aemail: linlinjlau@126.com
}

Keywords: Schooling quality; Guiding ideology; Universities with strengthened human resources; Combination of production and research

\begin{abstract}
Schooling quality and level is the lifeline of local universities' survival and development. This paper proposes strategic recommendations on improving schooling quality of local universities from the perspective of correct guiding ideology, creative talent training mechanism, and the combination of production and research.
\end{abstract}

\section{Introduction}

At present there are three categories of universities in China: comprehensive research university, local teaching oriented university of multidisciplinary or single disciplinary and vocational college. Most of them belong to local universities, primarily serving the economic and social development in the region ${ }^{[1]}$. It's no doubt that there is a beg difference between most of the local colleges and universities the domestic first-class universities and world-class universities in terms of educational philosophy, management system, faculty, academic level, school conditions due to the limitation of human, finance, and material recourses. Under the circumstance of the incentive competition of funding, school conditions and employment in the higher education market, within the environment of every university's desire to gain advantage in the competition environment with its excellent teaching quality and level, how to find their place in the competition and expand the space for survival and development, has become a problem that managers and even every faculty of the local colleges and universities must seriously think about.

Correct guiding ideology, fostering school characteristics, improving operating efficiency, taking a striding development, are the prerequisite for the survival, development, and competition of local colleges and universities.

Guiding ideology, refers to the ideas of talent quality standards and the correspondent assurance measures established by school's decision-making body based on the national education policy, education legislation, education law, the schools training objectives, and social realities. Its extension includes personnel training objectives (quality standards), route of personnel training (teaching position), and specific measures of assuring personnel quality ${ }^{[2]}$. Guiding ideology is the soul of a school which reflects the school's values in a deep level and fundamentally regulates the school's various behaviors. Schools without correct guiding ideology are likely to be eliminated by the torrent of higher education. The successful experience of various well-known Universities shows that nurturing school characteristics and taking the distinctive development road are not only the fundamental for colleges and universities' establishment and survival but also the prerequisite for their development and competition. 
It is impossible to be as comprehensive as some other national key universities to build local colleges and universities into high level universities with its own disciplinary advantages and scientific characteristics. We should not seek its full, but for its advantages; not for its large, but for its special. We should be clear of things we should do and things we should not. Only by this way can we concentrate the limited human, financial and material resources to fight battle and gain more, better, and larger achievements. Only by this way can we form the distinctive characteristics and advantages that can not be replaced by other schools ${ }^{[3]}$. Of course, although the local colleges and universities serve the local, they are dependent on the guidance of higher education and laws and dependent on the influences of the national and even global macro background of the development of higher education. Thus, even the local university must establish an open and international development orientation, comply with the trend of internationalization of higher education, and formulate the open development strategy based on localization at the same time.

In order to catch up or even surpass other schools in the near future, local colleges and universities must take extraordinarily striding development. As local colleges and universities, we should also stress the strategic development thinking and introduce the strategic development planning and management features of enterprise management into university to achieve the "discipline construction as a leader, teaching as the center, scientific research promoting teaching" and take the striding development path. The striding development must step the characteristics road. By observing the first-class universities abroad that have achieved striding development in a short period of time, we can find they all have distinct characteristics. Only by playing our specialty can we ascertain positioning and concentrate to form a breakthrough and stand out from the competition. Only by Only the formation of our own characteristics, can we form the school's unique core competitiveness to promote the school's overall and sustainable development. To create special disciplines, we need to dare to spend large amounts of money to build domestic first-class laboratory and struggle to possess a number of domestic first-class precision instruments and equipment. Meanwhile, we will take the domestic teacher guidance, study abroad, undertake national and local key scientific research projects and key transformation projects, and push the teacher to the front line of teaching and research to hustle in practical exercise. With China's sustained rapid economic development, the implementation of the strategy of building a moderately prosperous society provides very favorable conditions for the striding development of local colleges and universities. Therefore, we must have sufficient confidence and seriously study the successful experience of domestic and foreign first-level universities' getting ahead of others as latecomers and extraordinary development. Develop practical development goals according to our own circumstances and innovate educational ideas. Exploit Advantages of Backwardness and find a shortcut to catch up. Strive to realize the leaps and bounds in both establishing superiority discipline and training high-level talents and creating a high level of scientific and technological achievements for the community to provide a strong service.

\section{Train personnel based on student-oriented principles, improve teachers faculty with good talent, and implement talent strengthening school strategy}

Follow the student-oriented principle, hierarchical culture, and in-depth teaching. All the work of the school is around the students and without students it will become a river without water and a tree without root. Therefore, since students are the center of school, it must adhere to the philosophy of "people-oriented, student first" and make the appropriate teaching reform. At present, China's 
higher education has entered into the popularity ranks from the elite ranks, which proposes an inevitable requirement colleges and universities and their training model stepping from centralization to diversification. It not only requires different types of universities having different modes but also requires the same school's adaptation to the training modes needed by different students.

As local colleges and universities, although the training of professional high-tech applied talents is surely considered as the main training level, the cultivation of academic research complex personnel should also be our responsibility. This requires developing appropriate specifications and personnel training programs and making corresponding adjustments to adapt to the needs of the community and the educated individual's development in order to ensure to improve the quality of personnel training, which is a severe challenge for our management ${ }^{[3]}$. In Sichuan Agricultural University, just the horticultural major has made many personnel training programs according to personnel needs: "gardening professional training programs", "gardening professional (Accelerated Degree) training program", "gardening professional(vegetables direction) training programs", "gardening professional(fruit trees direction) training programs", "gardening professional (ornamental horticulture direction) training programs", etc. and it has to adjust professional direction annually and revise personnel training programs.

Construct teaching staff of high level, use human resources scientifically, improve the quality of education and quality levels. College is the main base of personnel training, the main producer and disseminator of science and technology and advanced culture. The volume and level of its faculty has become an important factor to judge the school level and core competitiveness and it has also become the key factor to determine the degree of the school's contribution to society ${ }^{[4]}$. The honor and development potential of a university lie in the quantity and quality of every generation of the teachers. From the school's point of view, promoting the healthy growth of talent and giving full play to the role should be put into the first place. scientifically develop and use human resources and promote the comprehensive development of talent.

Firstly, we must strive to utilize the local resources, make the best use of them, develop and train the existing talents in order to establish a faculty of sufficient number, rational structure and high standards. Secondly, vigorously implement the strategy of talents strengthening university from the three aspects of introduction, training and stability and persist in reform and innovation. Strive to take major policies and measures to actively improve teachers' work, study and living conditions. Reward teachers for outstanding contributions and form a standardized system of incentives. Break the bottleneck restricting the development of the schools and construct high-level, highly educated, and highly qualified teaching staff so as to enhance the quality of education and school level.

\section{Make full use of geographical advantages actively participate in local economic development, and take the road of combining production and research}

Local colleges and universities should strengthen the training of applied talents. They can widely establish the practice base with social employing units by entering into contracts and hire leaders who possess a strong base of business as a part-time professor, so that students can enhance practical ability at the base and be valued by employers. Select the appropriate profession, open the joint training path between schools and enterprises, and achieve the "marketability and short supply" of school graduates. The curriculum design in Hong Kong University is basic 
market-oriented and all its departments will invite the industry's most eminent persons to be involved in the design course content. Especially the Hong Kong Polytechnic University attaches great importance to the opinion of "employer". They do annual surveys of employers and get to know employers' opinion on the school curriculum, teaching methods and student ability and quickly make amendment in accordance with the views of these investigations. They also have plans to cultivate graduates funded by schools or the company sending graduates to the factory for practice.

\section{Conclusion}

School quality, school effectiveness and school levels complement each other and promote each other. Only by the continuous improvement of the quality of personnel training to meet the needs of society, can the size of students be possibly stabilized and expanded, and thus bring direct and stable benefits to the school. Only by the continuous improvement of operating efficiency, can the school conditions and the living conditions of staff be continuously improved in order to better promote the quality of personnel training and the improvement the educational level. Therefore, we must continue to change the educational ideas and form distinctive educational characteristics. Implement the strategy of talents strengthening school and innovate management system. Deepen the teaching reform and improve teaching quality and school level. Have a good reputation in the society, and then continue to expand enrollment. improve operating efficiency and, ultimately, gain the advantage and absolute competitiveness of survival and development in the higher education market.

\section{References}

[1] Wang Xiaoqing, Zhang Mengjie. Several problems of higher education institutions, Journal of Huanggang Normal University, 2007,27 (2), 85-86.

[2] Yang Youyong. A Research of Guiding Ideology for Higher Education, Journal of Hanzhong Normal University, 2001, 19 (2), 34-39.

[3] Lv Jiande. The guiding ideology of higher education institutions should adhere to the "student-centered", Journal of Henan Vocation-Technical Normal University, 2004,32 (3), 122-123.

[4] Zhang Lixin. Discussion on the connotation of "people-oriented" educational ideology of higher university. Journal of Xinjiang Normal University, 2005,26 (4), 225-227 